\title{
Utilização de água subterrânea em Frederico Westphalen-RS: condições sócioambientais dos usuários
}

\author{
Use of groundwater in Frederico Westphalen-RS: socio-environmental conditions of the users
}

Willian Fernando de Borba, Pedro Daniel da Cunha Kemerich, Pablo Ricardo Piceti Pretto, Leonidas Descovi Filho, Juliane Sapper Griebeler, Carlos Eduardo Balestrin Flores, Bruno Acosta Flores; Kelli Andreizza; Fabiane Toniazzo; Gabriel D’Avila Fernandes

Laboratório de Planejamento e Monitoramento Ambiental - LPMA/UFSM, Curso de Engenharia Ambiental da Universidade Federal de Santa Maria - UFSM/CESNORS

\begin{abstract}
Resumo
Com o crescente aumento dos níveis de contaminação do solo, as fontes alternativas de abastecimento de água estão se tornando uma ameaça a saúde da população que utiliza esse recurso. Sendo assim, o presente trabalho tem como objetivo determinar e avaliar as condições socioambientais dos usuários de fontes alternativas de abastecimento de água de Frederico Westphalen - RS. A avaliação foi feita através de visitas as residências e sendo aplicados questionários com varias perguntas referentes ao tema das fontes alternativas de abastecimento, no decorrer do ano de 2011 e 2012. O número de poços, os tipos, as localizações em coordenadas UTM, níveis estáticos e situações em que se encontravam foram levantados nessas visitas, além das condições sócio-ambientais dos usuários. Sendo assim, conclui-se que mesmo tendo acesso a rede pública de abastecimento, muitos usuários ainda utilizam as fontes alternativas para abastecimento de suas residências, sendo isso uma grande preocupação, pois muitos usuários não tem conhecimento da qualidade dessa água usada para o consumo.
\end{abstract}

Palavras-chave: Abastecimento, fontes alternativas, poços.

\begin{abstract}
With the increasing levels of soil contamination, alternative sources of water supply are becoming a threat to the health of the population that uses this feature. Thus, this study aims to determine and evaluate the social and environmental conditions of the users of alternative sources of water supply Frederico Westphalen - RS. The evaluation was done through visits to homes and by applying a questionnaire with several questions on the topic of alternative sources of supply, during the year 2011 and 2012. The number of wells, types, locations in UTM coordinates, static levels and situations they were in were raised in these visits. Therefore, it is concluded that even having access to the public network, many users still use alternative sources to supply their homes, this being a major concern, since many users are unaware of the quality of the water used for consumption.
\end{abstract}

Keywords: Supply, alternative Sources, wells. 


\section{INTRODUÇ̃̃O}

Segundo o relatório de Desenvolvimento Humano da Organização das Nações Unidas (2011), aproximadamente metade da população dos países em desenvolvimentos não dispõe de condições sanitárias básicas, o que contribui para que ocorra contaminação dos recursos hídricos, principalmente em relação a forma de despejo dos resíduos. Desta forma cresce a preocupação com a demanda hídrica para uso humano, descendentação animal e lazer, assim uma fonte alternativa utilizada atualmente é a água subterrânea.

Essas fontes quando relacionadas às águas superficiais apresentam a vantagem de baixos custos de captação, já que não há necessidades de obras de engenharia de alto valor econômico, para manutenção e disponibilidade. Outro fator importante, quando os poços são bem construídos dificilmente causam problemas ambientais (ZANATTA \& COITINHO, 2002).

Contudo, a população não está ciente dos riscos que essa alternativa apresenta. Há a falsa ilusão deste recurso estar bem protegido por estar circundado por rochas, no entanto, elas estão sujeitas a fonte de poluição ou contaminação natural, decorrente das características do tipo de solo da região (BRASIL, 2006).

Os contaminantes ao serem depositados, ou ao vazarem, ou ao se derramarem, em resumo, ao atingirem a superfície do solo, passam a se infiltrar lentamente pelo meio poroso, indo se encontrar com as águas do lençol freático, que é o primeiro e mais vulnerável aqüífero. O solo contaminado, por permitir uma lenta lixiviação de contaminantes para as águas subterrâneas, passa a se constituir numa fonte de contaminação armazenando fase residual de produto em seus poros (ABAS, 2013).

A qualidade da água não está claramente visível, uma vez que os perigos presentes são microscópicos, representados pelos microrganismos e pelos níveis alterados de substâncias inorgânicas, como flúor, por exemplo, isso acarreta riscos à saúde pública relacionados e distribuídos em duas categorias: 1) riscos relativos a ingestão de água contaminada por agentes biológicos (vírus, bactérias, parasitas); 2) riscos derivados de poluentes químicos, em geral, efluentes de esgotos industriais (KEMERICH \& SAUCEDO, 2011).

Preocupados com a gravidade da situação, criou-se esse trabalho que apresenta informações relativas às condições dos poços e fontes/nascentes da área urbana, das situações Sócio-Ambientais dos usuários dessas águas, gerando informações, não somente para o uso técnico-cientifico, mas também para o conhecimento da população, incentivando- a a conservar e proteger os mananciais e ainda melhorando as condições sanitárias e ambientais.

\section{MATERIAIS E MÉTODOS}

\section{I Caracterização da área em estudo}

Frederico Westphalen é um município brasileiro do estado do Rio Grande do Sul. Localiza-se a uma latitude $27^{\circ} 21^{\prime} 33^{\prime \prime}$ sul e a uma longitude $53^{\circ} 23^{\prime} 40^{\prime \prime}$ oeste, estando a uma altitude de 566 metros. Sua população, de acordo com a estimativa para 2007, é de 28.848 habitantes. Possui uma área de $264,975 \mathrm{~km}^{2}$, é o centro regional da microrregião homônima, pertence ao bioma da mata atlântica e seu clima é subtropical úmido (IBGE, 2010). A localização é ilustrada na Figura 1.

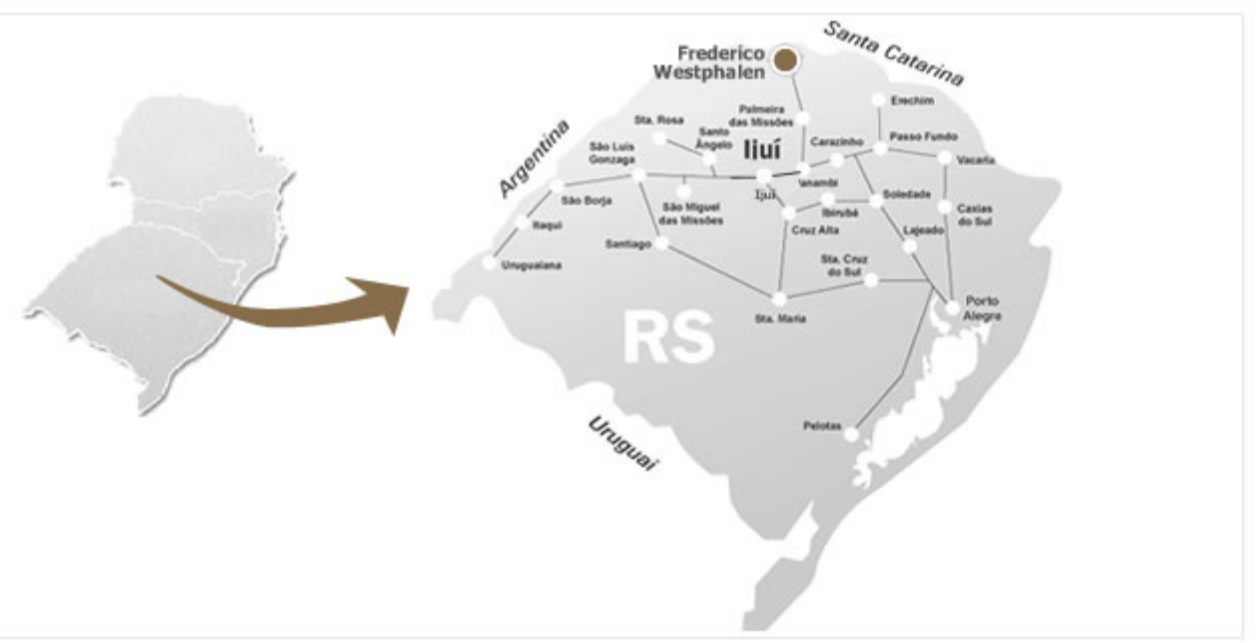

Figura 1. Localização do Município de Frederico Westphalen,

Fonte: http://www.google.com.br/imgres?imgurl). 


\subsection{Cadastramento das fontes alternativas de abastecimento}

O cadastramento das fontes alternativas de abastecimento foi realizado por meio de vizitas às residências, no período de 2 de maio de 2011 a 22 de junho de 2012, onde o número de poços, tipos, coordenadas UTM e situações, foram coletadas.

Os instrumentos utilizados foram uma planilha, na qual foram anotados os dados coletados, quanto à situação de funcionamento, uso da água e o tipo dos poços com o fim de gerar um cadastro; uma trena de 20 metros, um GPS topográfico, da marca Trimble, modelo GeoExplorer 3 e uma câmera digital Olympus FE 150.

\subsection{Usuários e condições de utilização das fontes alternativas de abastecimento}

O trabalho teve início com a aplicação de questionários a fim de obter informações sócio-ambientais a respeito dos usuários de fontes alternativas de abastecimento de água, objetivando-se o melhor conhecimento sobre os usuários de água subterrânea e a condição em que as fontes se encontram.

Onde os itens abordados no questionário foram os seguintes: escolaridade, renda familiar, número de pessoas da família, hábitos de higiene, conhecimento sobre doenças de veiculação hídrica, entre outros.

\section{RESULTADOS E DISCUSSÃO}

$\mathrm{Na}$ área urbana de Frederico Westphalen RS, nos bairros Barril, Panosso, Itapagé, Aparecida,
Fátima, Santo Antônio, Santo Inácio, Ipiranga, Centro e Jardim Primavera foram cadastrados um total de 71 fontes alternativas de abastecimento, sendo 6 fonte/nascente, 5 poços tubulares e 60 poços escavados, conforme ilustra a Figura 2.

\section{I Condições sócio-ambientais dos usuários das águas subterrâneas}

Na cidade de Frederico Westphalen - RS, através das visitas e aplicação dos questionários foi obtido, um total de 71 moradores usuários de fontes alternativas de abastecimento de água, com diferentes faixas etárias e condições sócio-econômicas diferentes. A renda familiar variava entre, menor que um salário mínimo em $24 \%$ (17/71) dos entrevistados, entre 1,1 a 1,9 salários mínimos em 19,7\% (14/71), entre 2 a 4,9 salários mínimos em 29,5\% (21/71), maior 5 salários mínimos em 14\% (10/71), não souberam ou não quiseram relatar $12,6 \%(9 / 71)$, representado na Figura 3 em forma de gráfico.

Com relação ao consumo de água desses entrevistados, 78,8\% (56/71) das pessoas, consomem água da Companhia Riograndense de Saneamento (CORSAN), 7\% (5/71) só consomem água de fontes alternativas (poços escavados, tubulares, etc..), $14 \%$ (10/71) consomem apenas água de poço comum, representado na Figura 4 em forma de gráfico. Kemerich (2008) em estudo semelhante na cidade de Santa Maria-RS, relatou que 37\% (40/109) dos usuários só consomem água provinda de poços tubulares, $7 \%(8 / 109)$ relataram tomar água de poço escavado e duas famílias relataram tomar água provinda de fontes nascentes.

Segundo CAJAZEIRAS (2007), a gravi-

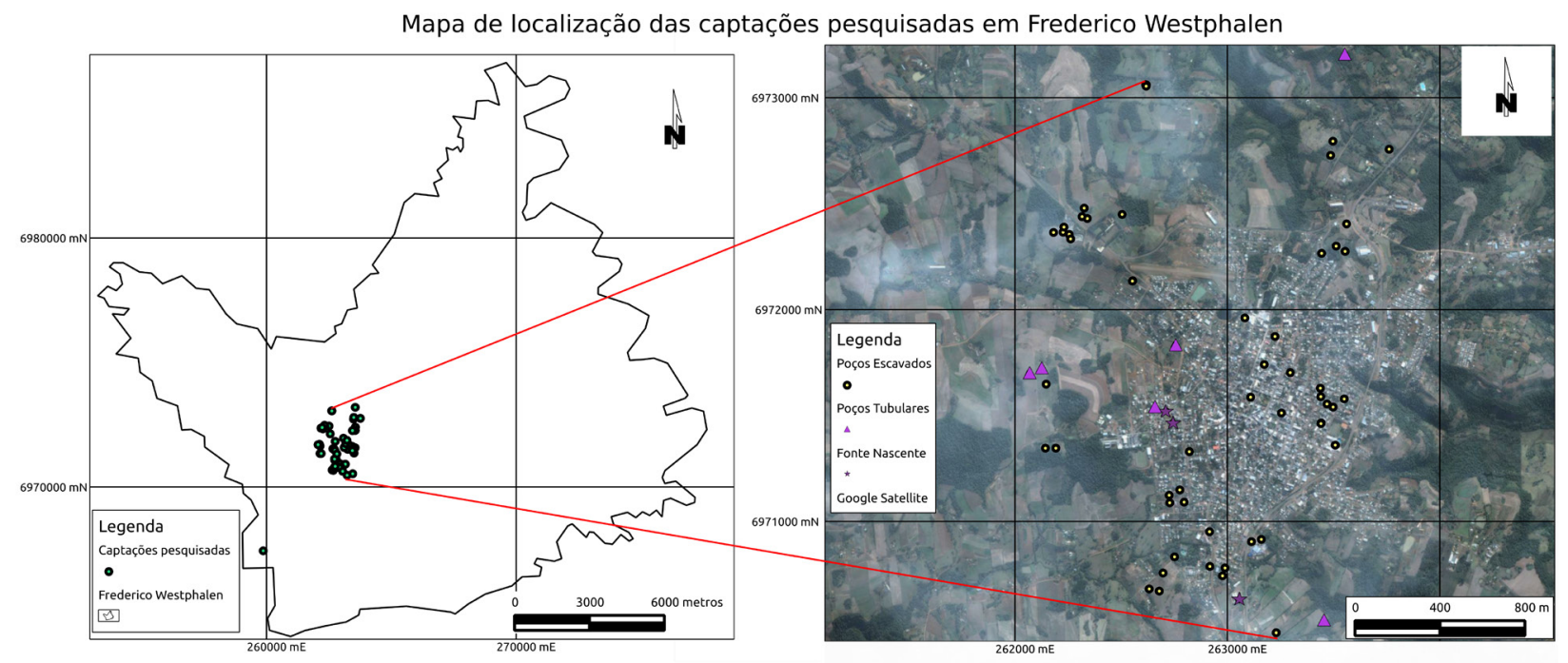

Figura 2. Localização das fontes alternativas de abastecimento de água na cidade de Frederico Westphalen - RS. 


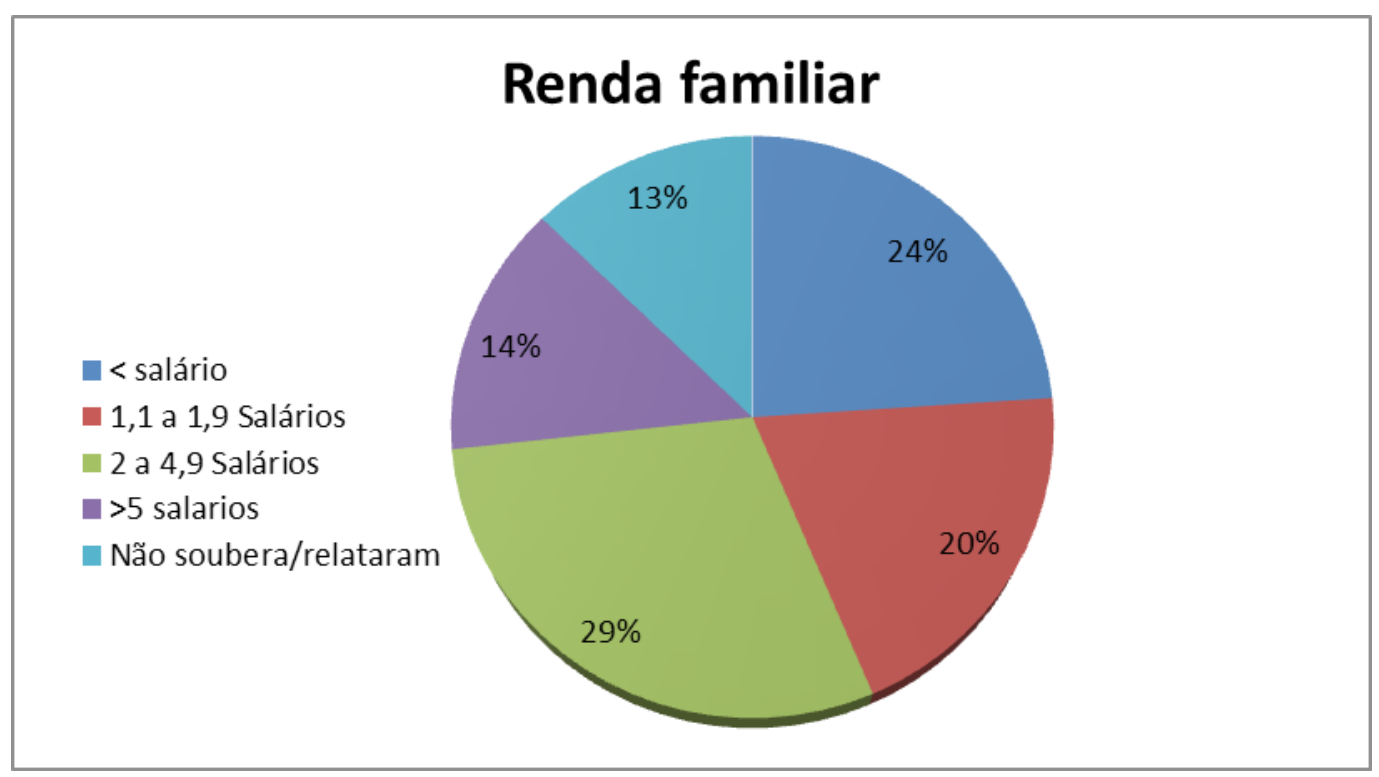

Figura 3. Renda familiar dos usuários.

dade do assunto pode ser percebida pelo que diz o capítulo 18 da Agenda 21 do plano mundial de metas ambientais estabelecidos na Eco92: "aproximadamente $80 \%$ de todas as doenças de origem hídrica e mais de um terço das mortes em países em desenvolvimento são causadas pelo consumo de água contaminada".

Quando perguntados se já tiveram algum tipo de instrução sobre problemas relacionados com a água, 40,8\% (29/71) dos entrevistados relataram que sim, enquanto que $59,15 \%(42 / 71)$ responderam que não ter tido nenhuma orientação sobre os problemas que podem ser provindos pela água, representados na figura 5. Em relação ao conhecimento das doenças que podem ser oriundas do consumo de água contaminada, 43,6\% (31/71) dos entrevistados afirmaram ter conhecimento, enquanto que 56\% (40/71) revelaram não ter conhecimento que a água contaminada poderia trazer malefícios à saúde humana, representado na Figura 6. Isso se torna uma grande preocupação, pois ALMEIDA (2006) diz que no Brasil, 65\% das internações hospitalares são provenientes de doenças de veiculação hídrica.

Perguntados sobre o hábito de ir ao médico, $59,1 \%(42 / 71)$ dos entrevistados vão frequentemente ao posto de saúde e (29/71) e $40,8 \%$ não tem o hábito de ir a consultas médicas frequentemente, representados na Figura 7.

Um fator relevante as questões de higiene,

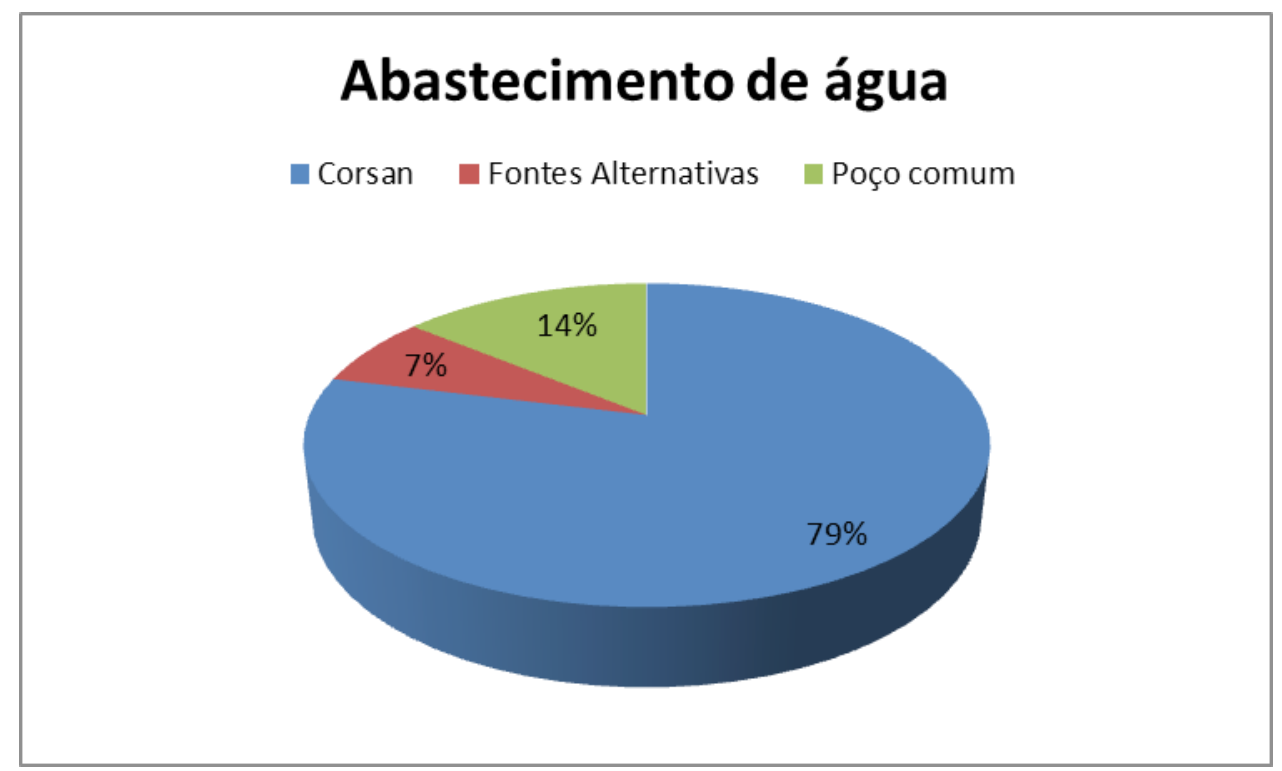

Figura 4. Percentual referente ao abastecimento de água da população de Frederico Westphalen - RS. 


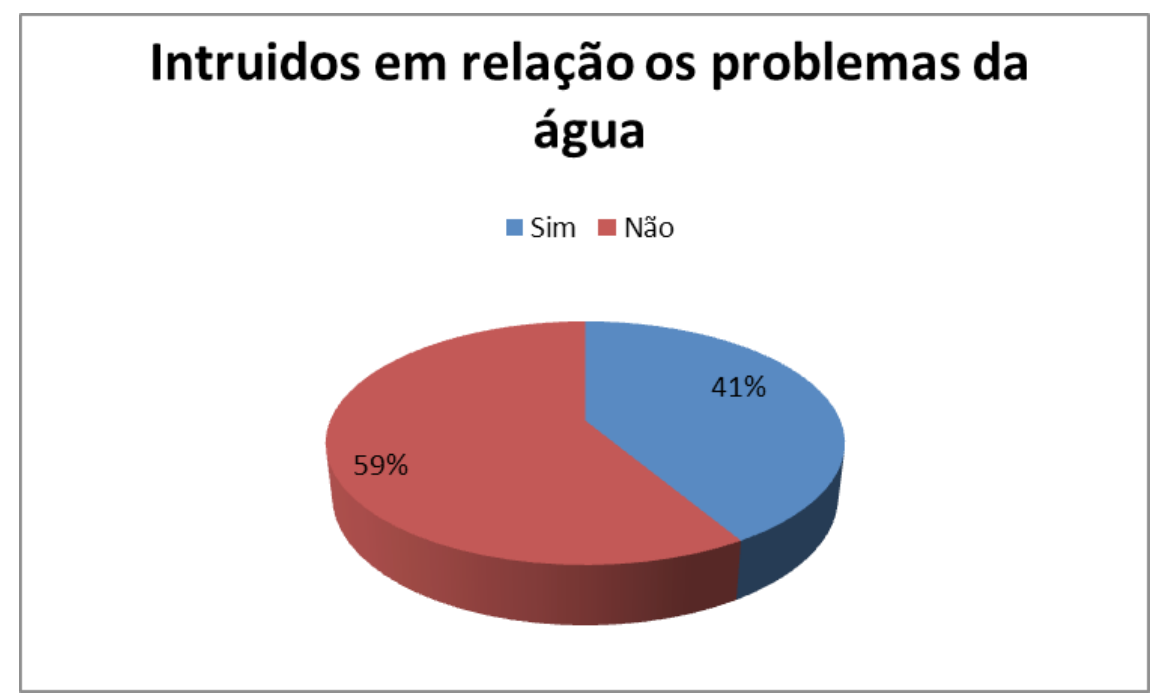

Figura 5. Percentuais da populaçao, que tiveram algum tipo de instrução sobre problemas relacionados com a água.

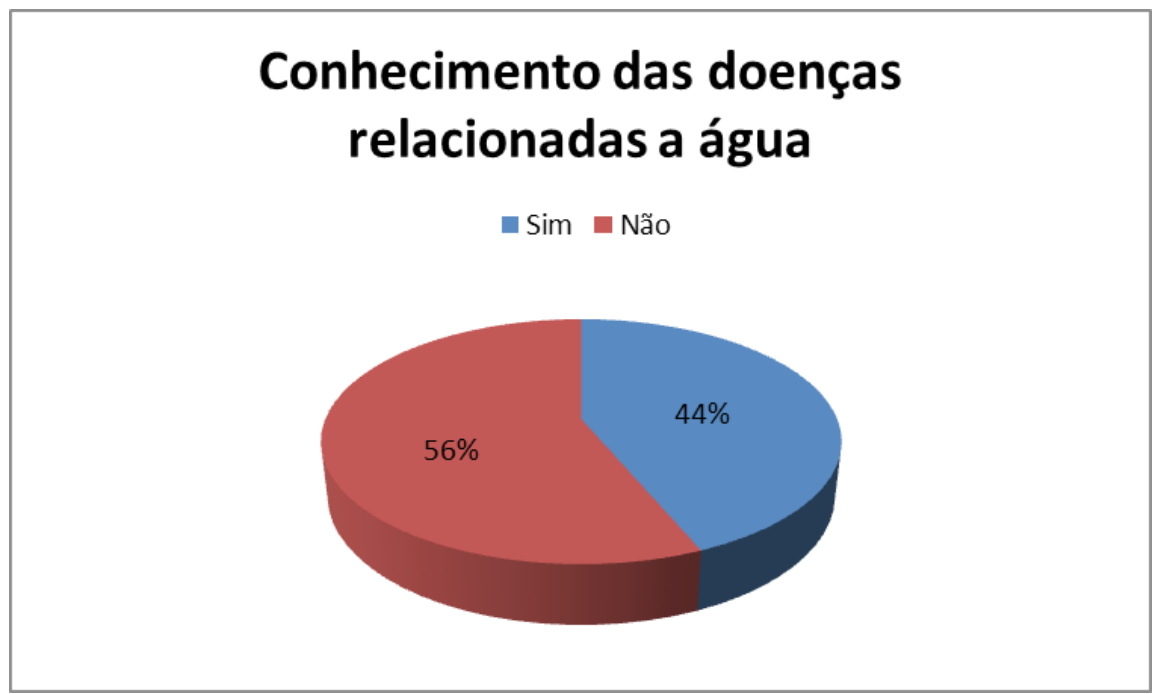

Figura 6. Percentual da população em relação ao conhecimento das doenças que podem ser oriundas do consumo de água contaminada.

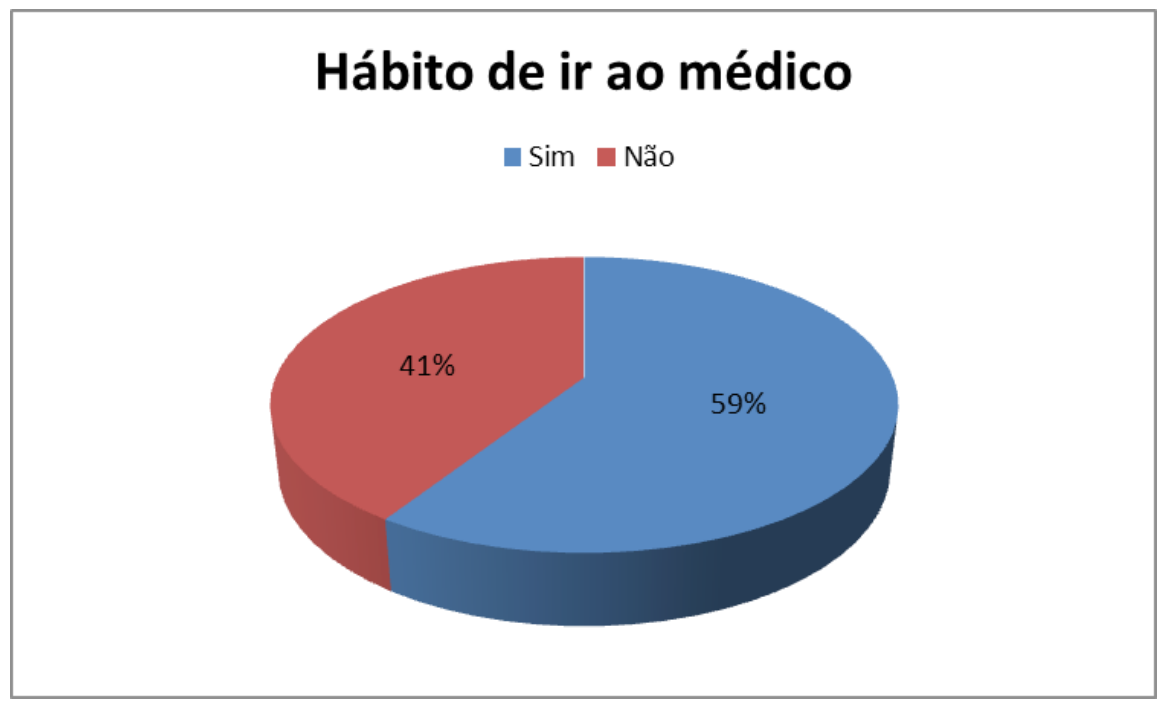

Figura 7. Percentual da população que tem hábito de ir ao médico. 


\section{Animais nas proximidades dos poços}

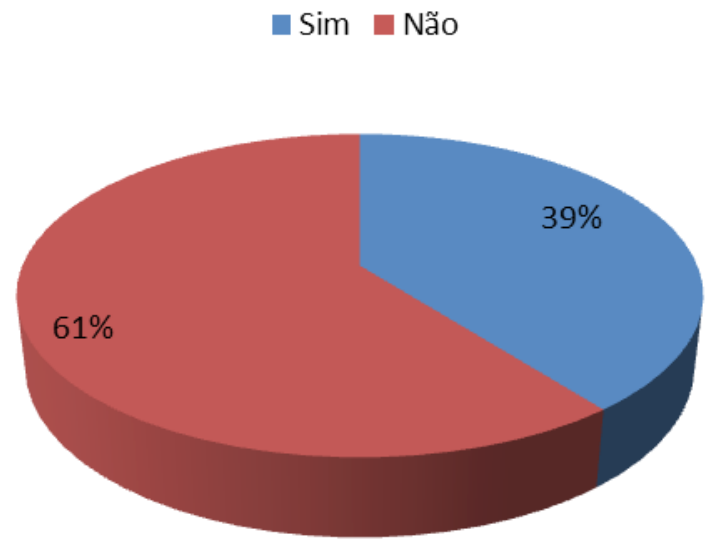

Figura 8. Percentual da população que possui criação de animais nas proximidade dos poços

é a presença de animais nas proximidades dos poços ou fontes, é algo que deve ser observado com cuidado, no presente estudo 39,4\% (29/71) dos entrevistados disseram que possuem animais de estimação e 60,5\% (42/71) disseram que não possuem, melhor representado na figura $8 \mathrm{em}$ forma de gráfico.

KEMERICH \& SAUCEDO (2011) afirmam que existe um alto risco para as doenças de veiculação hídrica, umas das principais no Brasil é a Hepatite A, logo sua disseminação está diretamente relacionada com o nível socioeconômico da população, ou seja condições de higiene e de saneamento ambiental. Quando questionados se tinham algum conhecimento sobre a hepatite $\mathrm{A}$, $91,5 \%(65 / 71)$ disseram que possuíam conhecimento sobre a doença, e 8,4\% (6/71) não sabiam explicar qual era a forma de transmissão, que se dá pela água ou por alimentos contaminados, representado na forma de gráfico na Figura 9.

Em relação aos reservatórios e a periodicidade de limpeza, 64 entrevistados, $(90,14 \%)$ disseram possuir reservatórios, representados em forma de gráfico na figura 10, destes $65,6 \%(42 / 64)$ declararam que os reservatórios são fechados com tampa e a periodicidade de limpeza é semestral, já 22 entrevistados, $(34,3 \%)$ disseram que os reservatórios não possuem tampa e não declararam a

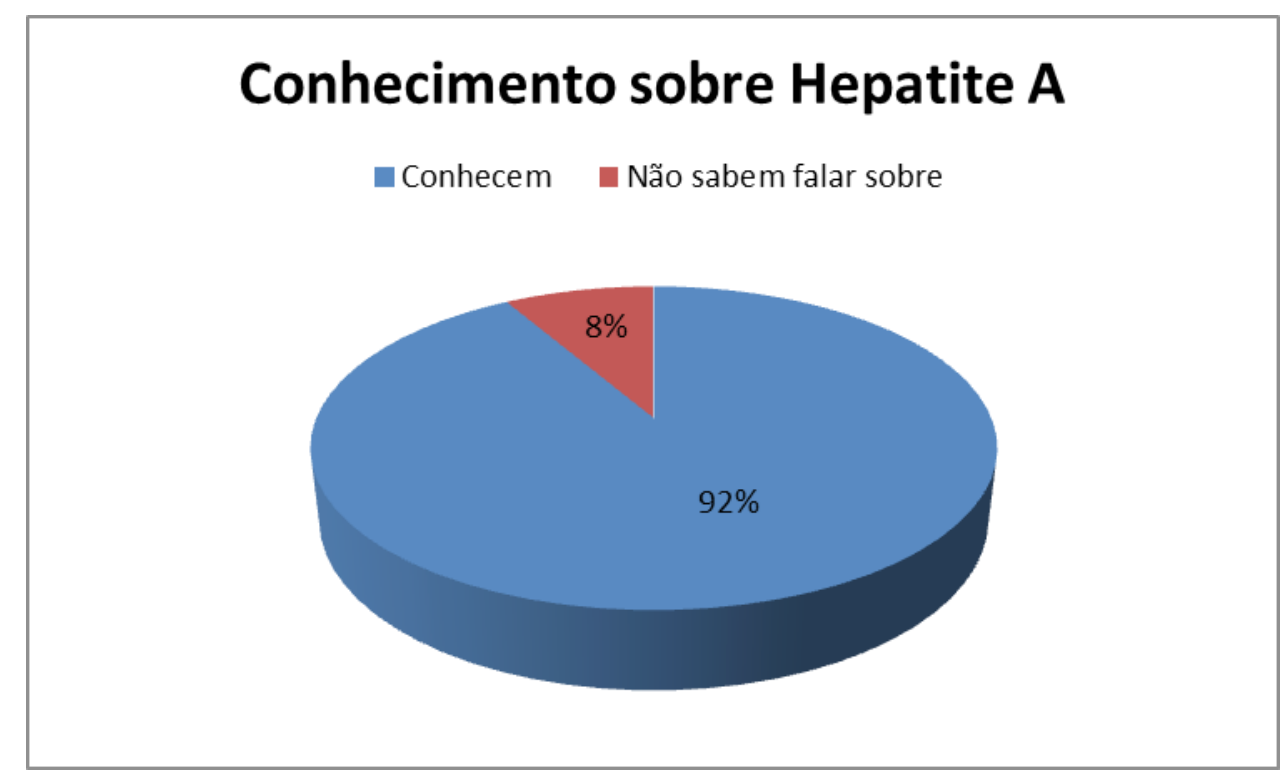

Figura 9. Percentual da população que possui conhecimento sobre hepatite A. 


\section{Presença de reservatório}

- Possuem reservatório $\quad$ Não possuem reservatório

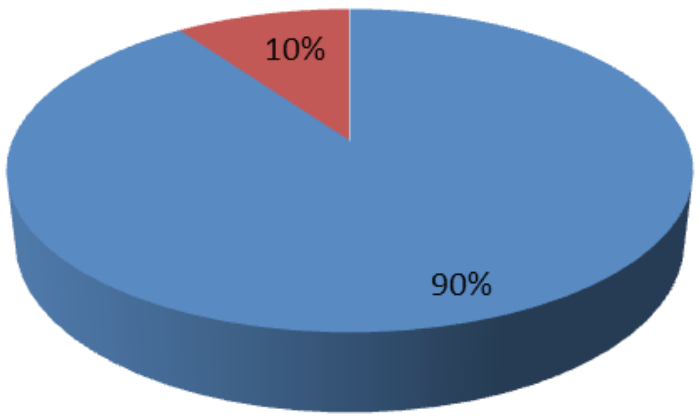

Figura 10. Percentual de recidencias com reservatórios no município de Frederico Westphaen.

\section{Condições dos reservatórios}

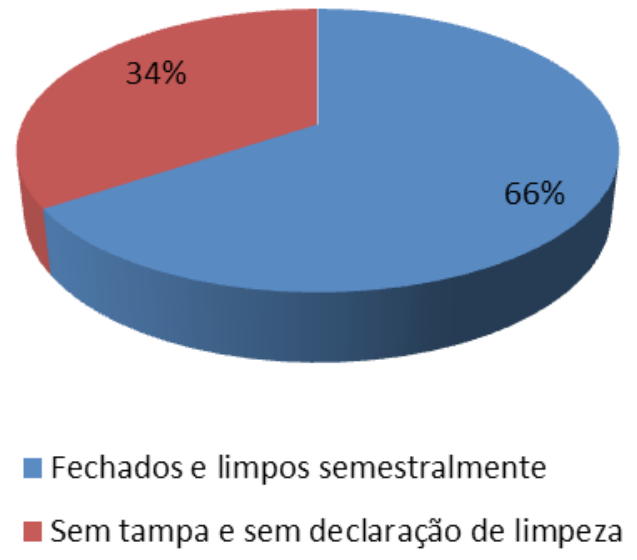

Figura 11. Condição dos reservaórios em relaçao a possuir tampa e em relaçao a limpeza.

periodicidade de limpeza, já 7 entrevistados $(9,8 \%)$ afirmaram que não possuem reservatório de água, possuindo conexão direta da fonte a residência, representados na Figura 11.

O resultado esperado a partir da aplicação do questionário é a conscientização da população, além do repasse de informações destes para as pessoas que com eles convivem, gerando ações dos próprios moradores em ter o cuidado com esse recurso natural disponível, assim, utilizando e preservando as características de uma água de boa qualidade ambiental.

Vale mencionar que, de acordo com a International Water Resources Association (IWRA), entre 8 milhões e 11 milhões de pessoas morrem anualmente no mundo devido a problemas relacionados ao controle da qualidade da água (doenças provenientes da contaminação) ou da quantidade (inundações e secas).

\section{CONCLUSÃO}

Com base nos resultados obtidos chegaram-se as seguintes conclusões:

Que os usuários dessas alternativas de abastecimento têm médios índices de conhecimento sobre cuidados e informações sobre doenças que esses meios podem causar isso faz que seja necessária a realização de análises de água, analisando a 
qualidade, evitando assim problemas com relação á água.

Pois com o aumento da contaminação do solo e dos recursos hídricos, essa massa populacional corre o risco de estar utilizando uma água fora dos padrões de potabilidade estabelecidos pelo Ministério da Saúde Portaria No 2.9140/ 2011.

\section{REFERÊNCIAS}

ASSOCIAÇÃO BRASILEIRA DE ÁGUAS SUBTERRÂNEAS - ABAS. Contaminação e remediação de águas subterrâneas. Disponível em: http:// www.abas.org/educacao contaminacao.php. Acessado em: 09 de Outubro de 2013.

BRAGA, B.; HESPANHOL, I.; CONEJO, J. G. L.; BARROS, M. T. L. De; PORTO, M.; NUCCI, N.; JULIANO, N.; EIGER, S. Introdução a engenharia ambiental. São Paulo: Pearson Prentice Hall, 2005.

BRASIL. Classificação e diretrizes ambientais para o enquadramento das águas subterrâneas e dá outra providência. Brasília, DF, Conselho Nacional de Meio Ambiente. Diário Oficial da União, Portaria n.2.914, 12 de dez, 2001.

CAJAZEIRA, C. C de A. Qualidade e uso das águas subterrâneas e a relação com doenças de veiculação hídrica, região de Crajubar/ CE. 2007. 131f. Dissertação (Mestrado em Geologia) - Programa de Pós-graduação em Geologia, Universidade Federal do Ceará, Fortaleza, 2007.

KEMERICH, P. D. da C. Água subterrânea e a saúde da comunidade em bairro de Santa Maria-RS. Dissertação (Mestrado em Engenharia Civil e Saneamento Ambiental) - Programa de Pós-Graduação em Engenharia Civil, Universidade Federal de Santa Maria, Santa Maria, 2008.

KEMERICH, P. D da C.; SAUCEDO, E. M. Saúde e condições sócio-ambientais de usuários de água subterrânea no bairro nossa senhora do perpétuo socorro de Santa Maria - RS. Engenharia AmbientalEspirito Santo do Pinhal, Vol.8, n.3, p.038-050, 2011.

MANASSÉS, F. Caracterização hidroquímica da água subterrânea da formação Serra Geral na região Sudoeste do Estado do Paraná. 2009. 136f. Dissertação (Mestrado em Geologia Ambiental) - Programa de Pós-graduação em Geologia, Universidade Federal do Paraná, Curitiba, 2009.
ORGANIZAÇÃO DAS NAÇÕES UNIDAS - ONU. Sustentabilidade e Equidade: Um Futuro Melhor para Todos. Relatório do desenvolvimento humano. Nova York: ONU, 2011.

ROHDE, F.; ROSSI, E. M.; SCAPIN, D.; CUNHA, F. P. Da; SARDIGLIA, C. U. Monitoramento microbiológico de águas subterrâneas em cidades do Extremo-Oeste de Santa Catarina. Ciência \& Saúde Coletiva, Vol.14, n.6, p. 2199-2203, 2009.

VERÍSSIMO, L. S.; MELO, F.; MENESES, F. A.; CARNEIRO, M. M. M. ALBUQUERQUE, V. C. Diagnóstico dos poços tubulares e a qualidade das águas subterrâneas no município de Campo Maior PI. XIII CONGRESSO BRASILEIRO DE ÁGUAS SUBTERRÂNEAS, 2004. Anais eletrônicos... Cuiabá: ABAS, 2004. Disponível em: http://www. cprm.gov.br/publique/media/diagnostico pocos.pdf. Acessado em: 10 de Julho de 2012.

ZANATTA, L. C.; COITINHO, J. B. L. Utilização de poços profundos no aquífero guarani para abastecimento público em Santa Catarina. XII CONGRESSO BRASILEIRO DE ÁGUAS SUBTERRÂNEAS, 2002. Anais eletrônicos... Florianópolis: ABAS, 2002. Disponível em: www. aquiferoguarani.ufsc.br/artigos/zanatta.pdf. Acessado em: 20 de Outubro de 2012. 